\title{
Clinical Trial Authorization
}

National Cancer Institute

\section{Source}

National Cancer Institute. Clinical Trial Authorization. NCI Thesaurus. Code C142440.

Authorization from an regulatory agency to undertake a clinical trial. 